УДК 616.006; 577.29

сКоллектив авторов

МОЛЕКУЛЯРНЫЕ МАРКЕРЫ РАКОВЫХ СТВОЛОВЫХ КЛЕТОК, ВЕРИФИЦИРОВАННЫЕ IN VIVO

\author{
Я.С. Ким ${ }^{1 *}$, А.М. Кайдина ${ }^{1}$ Ю.Х. Чанг², К.Н. Ярыгин ${ }^{1}$, А.Ю Лупатов ${ }^{1}$
}

'Научно-исследовательский институт биомедицинской химии имени В.Н. Ореховича, 119121, Москва, Погодинская ул. 10; тел.: +7 (499) 246-86-22; эл. почта: yankimhcc@gmail.com

${ }^{2}$ Национальный университет Чжэн Чэнгуна, Тайнань, Тайвань

\begin{abstract}
Системный обзор посвящен выявлению молекулярных маркеров раковых стволовых клеток, значимость которых подтверждена в экспериментах по трансплантации опухолевых субпопуляций с различным фенотипом иммунодефицитным животным. Было отобрано 97 статей, полностью соответствующих задачам исследования. Результаты их анализа свидетельствуют, что наиболее часто используемыми для выделения раковых стволовых клеток маркерами являются: CD133, CD44, ALDH, CD34, CD24 и ЕрСАM. В обзоре также приведены молекулярные особенности и свойства ряда маркеров раковых стволовых клеток, рассматриваются подходы к терапии опухолей, направленные против этой клеточной субпопуляции, оцениваются перспективы дальнейшего развития теории раковой стволовой клетки.
\end{abstract}

Ключевые слова: раковая стволовая клетка, молекулярные маркеры, системный обзор

DOI 10.18097/PBMC20166203228

\section{ВВЕДЕНИЕ}

Непрерывный рост количества публикаций, посвящённых исследованию клеточной гетерогенности опухолевой ткани, отражает актуальность этого направления, как для понимания фундаментальных основ канцерогенеза, так и для развития новых методов терапии онкологических заболеваний. Одной из концепций, обосновывающих существование клеточной гетерогенности опухолей, является теория раковой стволовой клетки (РСК). В данном системном обзоре мы приводим результаты анализа использования различных молекулярных маркеров для выделения популяций РСК из опухолевой ткани. В анализ включены только работы, в которых проведена проверка способности РСК выступать в качестве опухоль-инициирующих клеток в экспериментах in vivo. Важность подтверждения этого свойства часто недооценивается исследователями, что приводит к размыванию изначальных представлений о РСК. В обзоре приведены известные биологические функции и свойства поверхностных молекулярных маркеров, которые в оригинальных работах наиболее часто используются для идентификации и выделения РСК, а также рассматриваются современные подходы к таргетной терапии и иммунотерапии опухолей, использующие РСК в качестве мишени. Выявление и изучение новых маркеров РСК позволит использовать их для разработки современных протоколов терапии и прогностической оценки течения онкологических заболеваний, а также позволит взглянуть по-новому на процесс инициирования и развития опухолей у человека.

\section{1. ТЕОРИЯ РАКОВОЙ СТВОЛОВОЙ КЛЕТКИ}

Феномен гетерогенности опухолевой массы давно знаком исследователям: еще в начале 19-го века учёные заметили, что даже на макроскопическом уровне ткань солидных опухолей может быть крайне неоднородной. В дальнейшем в процессе развития гистологических методов гетерогенность была показана и на клеточном уровне. На этом основании был высказан ряд гипотез, которые были призваны помочь в объяснении клеточного плейоморфизма новообразований. Одной из них была гипотеза о возникновении всей массы опухолевых клеток из популяции низкодифференцированных клеток опухоли, обладающих определенными “стволовыми” свойствами. Таким образом, клеточная структура новообразования имитировала структуру нормальной ткани с ее иерархией и гетерогенностью. Косвенные факты в подтверждение этой гипотезы представляли те или иные группы исследователей на протяжении всего 20-го века [1-3], что позволило в 1988 г. сформулировать окончательный вариант концепции “опухоли как карикатуры нормального процесса самообновления ткани” [4]. Несмотря на то, что её автор отстаивал лишь отчасти верную идею о том, что опухоль является более примитивной стадией развития той ткани, из которой она произошла, это была одна из первых теорий, идейно связавших стволовую и опухолевую клетки. Её концепция, как и ряд других, стали предпосылкой формирования современной теории раковой стволовой клетки (РСК).

Теория РСК, сформулированная в 1997 г. [5], базируется на утверждении, что в структуре популяций опухолевых клеток существует чёткая иерархия, на вершине которой находится популяция трансформированных клеток, которые имеют свойства сходные со свойствами нормальных стволовых клеток. Подобно другим стволовым клеткам РСК способны поддерживать свою популяцию, в том числе за счёт ассиметричного деления [6], в результате которого возникают как новые РСК, так и более 


\section{МОЛЕКУЛЯРНЫЕ МАРКЕРЫ РАКОВЫХ СТВОЛОВЫХ КЛЕТОК}

дифференцированные раковые клетки. При этом РСК обладают исключительной туморогенностью. Способность нормальных стволовых клеток к миграции в повреждённые ткани, необходимая для успешной регенерации, в случае РСК выражается в инвазии и метастазировании $[7,8]$. Повышенная устойчивость стволовых клеток к воздействию ксенобиотиков, обусловленная увеличением активности белков-транспортеров и ферментов группы альдегиддегидрогеназы, проявляется в устойчивости РСК к химиотерапии [9]. При этом РСК, сохранившиеся после химиотерапии, в отличие от клеток других популяций раковых клеток, способны к восстановлению исходного популяционного разнообразия опухолевой массы. Результаты клинических исследований свидетельствуют о существовании корреляции между экспрессией маркеров РСК и плохим прогнозом и метастазированием [10-12].

По-видимому, в большинстве случаев РСК возникают из региональных стволовых клеток, которые имеют достаточный пролиферативный потенциал для накопления мутаций, приводящих к злокачественной трансформации. Предположение о наличии в опухоли небольшой субпопуляции клеток, поддерживающей гетерогенность опухолевой ткани и ответственной за рецидивирование, метастазирование и резистентность опухоли к терапии, отличает теорию РСК от теории клональной эволюции [5]. В рамках теории клональной эволюции в качестве причины клеточной гетерогенности рассматривается естественный отбор клеточных клонов, наиболее приспособленных к росту в составе опухоли [13]. Интересно отметить, что в контексте теории РСК гетерогенность клеток опухоли, как фенотипическая, так и функциональная, по-видимому, связана с эпигенетическими различиями, а не с генетическими изменениями, как это следует из теории клональной эволюции [14]. Несмотря на то, что теория РСК и теория клональной эволюции базируются на различных принципах, они не являются взаимоисключающими. По-видимому, сами РСК могут подвергаться клональной эволюции с образованием более злокачественных субпопуляций. Кроме того, не исключено, что из раковых клеток, подвергнутых в той или иной степени дифференцировке, в результате мутаций, обусловленных их генетической нестабильностью, могут образовываться клоны c эпигенетическими паттернами, характерными для стволовых клеток и свойствами РСК. В настоящее время не возникает сомнений по поводу того, что селекция наиболее злокачественных опухолевых клеток оказывает существенное влияние на опухолевую прогрессию.

В практическом плане теория РСК позволяет взглянуть по-новому на разработку эффективных способов терапии онкологических заболеваний. Поскольку, согласно этой теории, только популяция РСК обладает туморогенными свойствами и способна поддерживать рост и метастазирование опухоли, становится критически важным направленное уничтожение именно этих клеток.

\section{2. МОЛЕКУЛЯРНЫЕ МАРКЕРЫ РАКОВЫХ СТВОЛОВЫХ КЛЕТОК ЗЛОКАЧЕСТВЕННЫХ НОВООБРАЗОВАНИЙ ЧЕЛОВЕКА}

Для системного обзора с целью извлечения информации о молекулярных маркерах РСК мы отбирали научные статьи с описанием экспериментальных работ, в которых авторы идентифицируют молекулы, характерные для РСК различных злокачественных опухолей человека. В анализ не были включены работы, выполненные на клеточных линиях. Обязательным условием включения данных в анализ было наличие в статье информации о верификации функциональных свойств РСК с использованием в качестве модели иммунодефицитных животных. На сегодняшний день практика применения иммунодефицитных мышей для доказательства наличия у изучаемых клеточных популяций свойств РСК является “золотым стандартом”. Выделенные популяции опухолевых клеток инокулируют подкожно, внутривенно или ортотопически в тело мыши с иммунодефицитом [15]. При этом методом последовательных разведений определяют минимальное количество клеток, при котором произошло инициирование роста опухоли и делают вывод о туморогенном потенциале введенных клеточных популяций.

Для поиска статей по теме обзора использовали платформу "PubMed" и следующие поисковые запросы: ((stem[title/abstract] OR progenitor[title/abstract] OR initiating[title/abstract]) AND (cancer[title] OR tumor[title] OR tumour[title] OR carcinoma[title] OR malignancy[title] OR lymphoma[title] OR leukemia[title] OR melanoma[title] OR glioma[title] OR glioblastoma[title] OR astrocytoma[title] OR neuroblastoma[title] OR sarcoma[title])) AND ((nude[title/abstract] OR nsg[title/abstract] OR scid[title/abstract] OR immunodeficient[title/abstract] OR immunocompromised[title/abstract] OR immunodeficiency [title/abstract]) AND (mice[title/abstract] OR mouse[title/abstract])) NOT "cell line"[title/abstract] NOT "cell lines" [title/abstract]. Введены ограничения по языку - "English" и биологическому виду - "Нuman". В результате поискового запроса было найдено 768 оригинальных работ, из которых мы отобрали 97 статей, которые полностью отвечали требованиям исследования и были проанализированы в дальнейшем.

Информация об использовании маркеров РСК, полученная в результате анализа отобранных статей, приведена в приложении (таблица). Диаграмма, демонстрирующая общее число работ, в которых были использованы маркеры РСК, приведена на рисунке 1.

Интересно, что лишь в небольшой части представленных работ была продемонстрирована исключительная туморогенность популяций РСК. В большинстве случаев клетки всех изучаемых популяций обладали в той или иной степени способностью инициировать опухоль in vivo. Исключительная туморогенность в изученных работах часто была сопряжена с ограниченным диапазоном разведений клеток, а также небольшим количеством используемых в работе животных. 


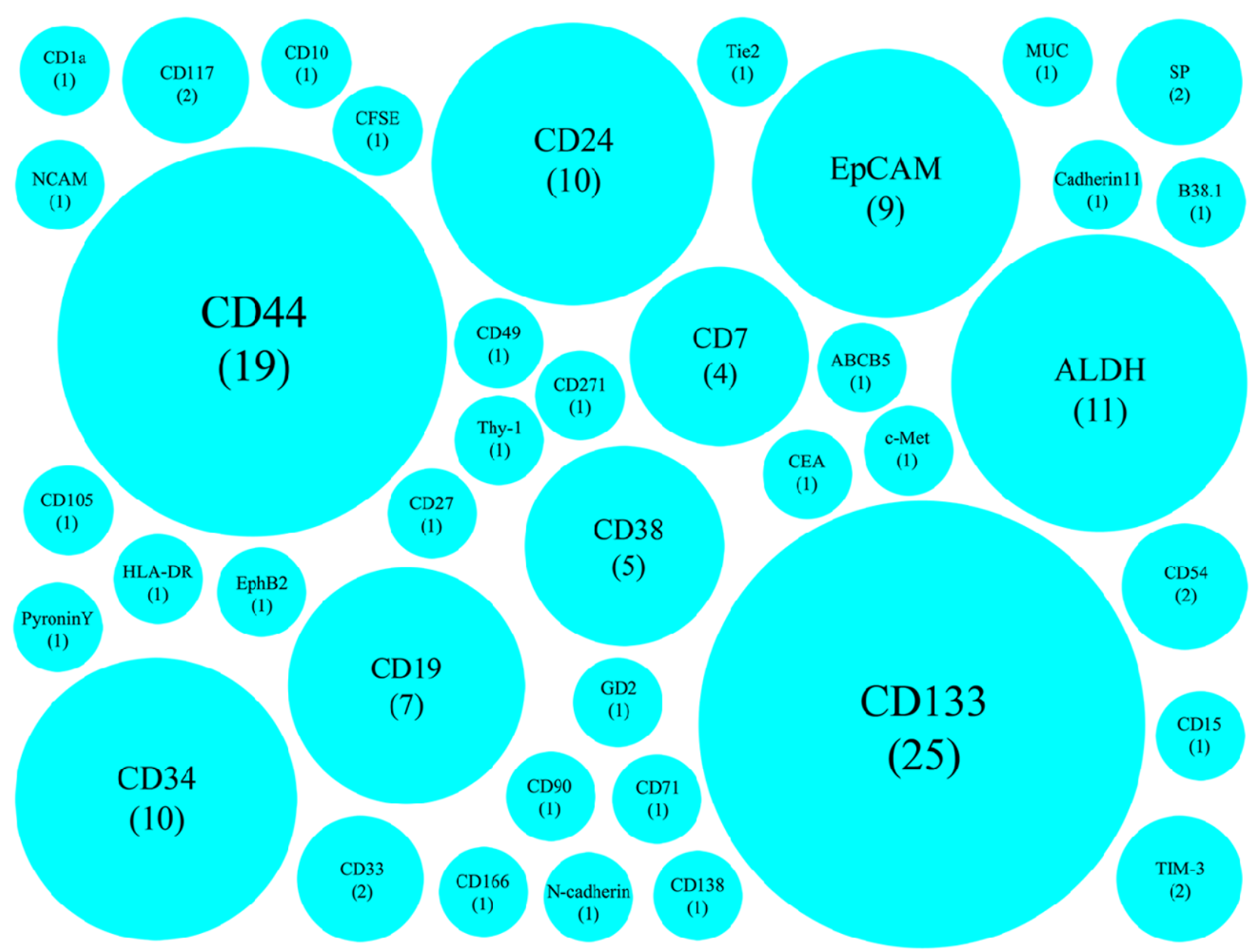

Рисунок 1. Количество публикаций, представляющих определённые дифференциальные маркеры РСК, верифицированные in vivo. В скобках - количество оригинальных публикаций. Площадь круга пропорциональна количеству работ.

Исходя из результатов системного обзора, чаще всего для выделения РСК в изученных работах использовали маркер CD133 (проминин-1). Его применяли для выделения инициирующих опухоль популяций в 25 работах, большая часть из которых была посвящена опухолям нервной ткани и различным карциномам (рис. 2). Второй по частоте использования маркер, $\mathrm{CD} 44$, применяли для выделения РСК в 19 работах, девять из которых проведены на образцах рака молочной и поджелудочной желез. На третьем месте по частоте использования находятся сразу четыре маркера примерно с одинаковым количеством работ: ALDH (11 работ), CD34 и CD24 (по 10 работ) и $\mathrm{EpCAM} \mathrm{(9} \mathrm{работ).} \mathrm{Использование} \mathrm{CD34}$ практически полностью было ограничено случаями гематологических опухолей и лишь в одной работе его применяли для выделения РСК из нейробластомы. CD24 чаще всего использовали для выделения РСК из опухолей молочной железы, а ЕрСАМ для выделения РСК из широкого спектра карцином. В свою очередь, использование ALDH не имело строгой опухолевой специфичности - этот маркер использовали для выделения РСК как из различных солидных опухолей, так и гемобластозов.
Интересно, что маркер эпителия ЕрСАМ, который часто используется как дифференциальный маркер эпителиальных опухолей при их отделении от клеток стромы, по-видимому, может выступать и в качестве маркера РСК. Это косвенно подтверждается данными о его роли в биологии нормальных стволовых и прогениторных клеток. Так, например, в ряде нормальных эпителиальных тканей экспрессия ЕрСАМ повышена в делящихся клетках, понижена в более дифференцированных потомках и крайне незначительна или отсутствует в терминально дифференцированных клетках [16].

\section{3. СТРУКТУРНО-ФУНКЦИОНАЛЬНЫЕ ОСОБЕННОСТИ НАИБОЛЕЕ ЧАСТО ИСПОЛЬЗУЕМЫХ МАРКЕРОВ РАКОВЫХ СТВОЛОВЫХ КЛЕТОК}

\subsection{CD133 (проминин-1)}

Проминин-1 - наиболее часто используемый для выделения популяции РСК из различных опухолей маркер. Этот гликопротеин с молекулярной массой 120 кДа принадлежит к семейству белков, содержащих пять трансмембранных доменов (5-TM). 

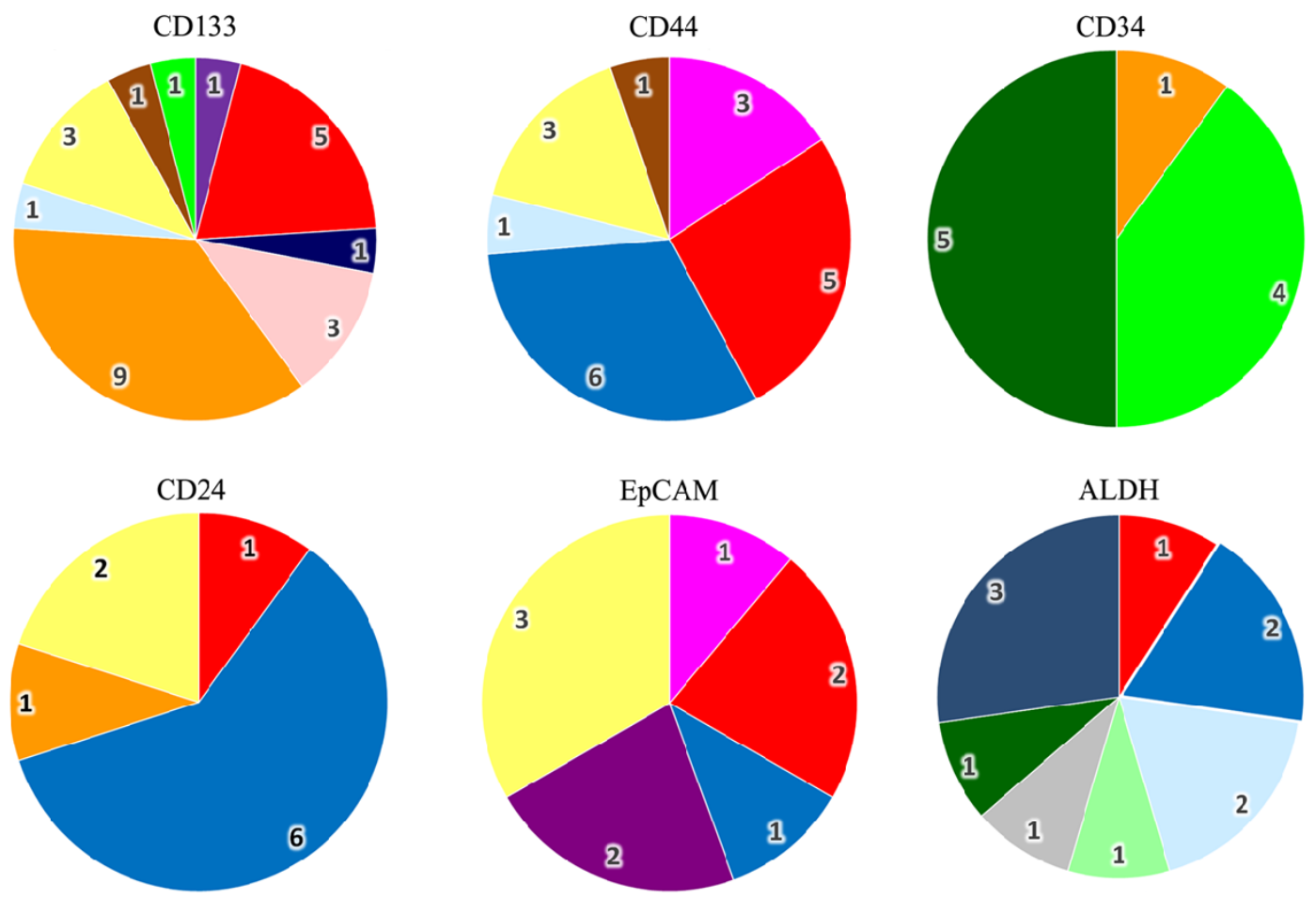

Нервная система

Молочная железа

Поджелудочная железа

Опорно-двигательная система

Яичник Желчный пузырь Лимфоидная ткань

Органы головы и шеи

Кишечник

Легкие

Миелоидная ткань

Кожа Почка

Рисунок 2. Использование дифференциальных маркеров для выделения РСК из опухолей различных локализаций. Опухоли сгруппированы по признаку органа или системы органов, в которых локализован первичный опухолевый очаг. В сегментах круга приведено количество работ, в которых используются обозначенные маркеры.

Его внеклеточная часть состоит из $\mathrm{N}$-концевого фрагмента, а также двух больших петель, каждая из которых имеет четыре потенциальных сайта для гликозилирования. Цитоплазматическая часть проминина-1 включает С-концевой фрагмент и две небольшие богатые цистеином петли [17]. На сегодняшний день известно, по крайней мере, семь различных изоформ проминина-1 с неясным различием в биологических функциях [18].

Впервые проминин-1 был обнаружен как маркер гемопоэтических стволовых и прогениторных CD34+ клеток в 1997 г. [17, 19]. Впоследствии его экспрессия была показана и в ряде других популяций нормальных стволовых и прогениторных клеток различных тканей $[20,21]$. Позднее, CD133 как маркер популяции РCK был обнаружен при различных новообразованиях человека, таких как, карцинома лёгкого, толстой кишки, поджелудочной железы, яичника, желчного пузыря, плоскоклеточный рак головы и шеи, глиобластома и ряд других онкологических заболеваний (см. таблицу в приложении). Необходимо отметить, что при сравнении нормальной и опухолевой ткани количество положительных по CD133 клеток в подавляющем большинстве случаев было существенно больше в последней [22-24].

Говоря о современных воззрениях на биологические функции CD133 необходимо отметить несколько фактов. Во-первых, у мышей с нокаутом по гену проминина-1 происходит постнатальная деградация фоторецепторов (как колбочек, так и палочек), приводящая к полной потере зрения [25]. Во-вторых, вне зависимости от типа клеток проминин-1 сконцентрирован на мембранных выростах, таких как микроворсинки и первичные реснички [26, 27$].$ Интересно, что подобные выросты могут специфически отделяться от клеток вместе с проминином-1, образуя так называемые микрочастицы, предположительно служащие либо для межклеточной коммуникации, либо для избавления от специфического на определённой стадии развития клетки мембранного микродомена $[28,29]$. И, наконец, в-третьих, проминин-1 связывается с мембранным холестерином, а также, возможно, с рядом ганглиозидов [30, 31]. Суммируя эти факты, можно предположить, что проминин-1, способный связываться с мембранным холестерином, участвует в организации структуры различных выростов плазматической мембраны и локальных мембранных доменов. Однако эти функции не объясняют роль проминина-1 в нормальной стволовой клетке или РСК. Таким образом, на сегодняшний день нет чётко сформированного представления об участии CD133 в их жизнедеятельности.

Отдельного обсуждения требуют работы последних лет, которые посвящены мета-анализу данных о корреляции уровня экспрессии CD133 


\section{Ким и др.}

в опухолях с течением заболевания и его клиникопатологическими характеристиками. Так, в четырёх работах, посвященных изучению немелкоклеточного рака лёгких, исследователи приводят данные о корреляции между экспрессией CD133 с более низкой общей выживаемостью $[11,32,33]$, наличием метастазов в лимфатические узлы $[11,33,34]$, а также с более низкой степенью дифференцировки клеток опухоли [11, 32, 34]. Результаты трёх подобных мета-анализов в отношении злокачественной глиомы также показывают статистически значимую корреляцию между экспрессией CD133 и более низкими общей выживаемостью [35-37] и выживаемостью без прогрессирования заболевания $[35,37]$, а также третьей и четвёртой стадиями прогрессии глиомы [36]. Проведено два подобных исследования в отношении колоректальной карциномы $[38,39]$ и два для карциномы желудка [40, 41], в которых также демонстрируется корреляция между повышенной экспрессией проминина-1 и низкой общей выживаемостью. В случае гепатоклеточной карциномы уровень экспрессии проминина-1 коррелирует с низкой дифференцировкой клеток опухоли, третьей и четвертой стадией прогрессии, сосудистой инвазией, а также с пониженной общей и безрецидивной выживаемостью [42]. В другой работе обнаружена корреляция между экспрессией $\mathrm{CD} 133$ и низкой двухлетней выживаемостью пациенток с третьей и четвёртой стадией карциномы яичника [43]. Таким образом, во всех вышеприведенных мета-анализах, суммарно проанализировавших более ста оригинальных работ, показана четкая взаимосвязь между повышенной экспрессией CD133 и неблагоприятным прогнозом течения онкологического заболевания.

Столь наглядные данные, касающиеся выделения сверхтуморогенных популяций с помощью маркера $\mathrm{CD} 133$, а также данные, связанные с корреляцией уровня экспрессии CD133 и тяжести течения заболевания, говорят об участии проминина-1 в процессе формирования различных опухолей. Это делает крайне интересным изучение функций этого маркера в биологии РСК.

\section{2. $C D 44$}

CD44 - трансмембранный гликопротеин, ген которого у человека локализован на 11-й хромосоме и включает двадцать экзонов; пять первых (1-5) и пять последних (16-20) экзонов являются константными для подавляющего большинства изоформ [44]. Пять первых экзонов кодируют внеклеточный глобулярный $\mathrm{N}$-концевой домен белка, отвечающий за взаимодействие с лигандами, в первую очередь, с гиалуроновой кислотой (гиалуронат), являющейся одним из главных компонентов внеклеточного матрикса [45]. Помимо гиалуроната этот глобулярный домен также может связываться с коллагеном, ламинином [46], фибронектином [47] и некоторыми рецепторами, такими как P-/L-/Е-селектин [48]. Десять вариабельных экзонов 6-15, которые обозначаются от "v1" до "v10", кодируют внеклеточный участок белка, располагающийся в непосредственной близости от плазматической мембраны и отвечающий за силу связывания изоформ CD44 с гиалуронатом. Кроме того, различные варианты этого домена позволяют взаимодействовать изоформам CD44 с множеством ростовых факторов, нерецепторными тирозинкиназами и рецепторами, такими, например, как рецептор фактора роста эндотелия сосудов (VEGFR) [49], основной фактор роста фибробластов (b-FGF) и гепарин-связывающий эпидермальный фактор роста (HB-EGF) [50]. Изоформа CD44 без вариабельных экзонов обозначается как CD44s (standard) и экспрессируется практически во всех тканях организма, тогда как изоформы $\mathrm{CD} 44 \mathrm{v}$ ограничены по экспрессии определенными тканями [51]. Помимо своей классической рецепторной функции связанный с лигандом CD44 может интернализироваться, а расщеплённая протеазами часть его внутриклеточного домена - транслоцироваться в ядро [52] и участвовать в регуляции экспресиии ряда генов, например, циклина D1 [53].

РCК, подобно нормальным стволовым клеткам, нуждаются в определенном микроокружении, которое необходимо для их функциональной активности. В ряде исследований обнаружен высокий уровень экспрессии гиалуроната (главного лиганда CD44) как непосредственно в самих стволовых клетках, так и в клетках их ниш $[54,55]$. Кроме того, трансфицированные CD44 клетки COS-7, исходно CD44 не экспрессировавшие, после добавления в среду гиалуроната и ряда протеогликанов обретали способность связывать гиалуронат и формировать внеклеточный матрикс [56]. Ряд других исследований демонстрирует влияние различных изоформ CD44 на расселение (хоуминг) гемопоэтических стволовых клеток [57], миграцию мезенхимальных стволовых клеток [58], специфичность дифференцировки CD34+ тимоцитов [59].

CD44 является маркером РСК при различных опухолях человека: колоректальной карциноме, раке желудка, раке поджелудочной и молочной желез, плоскоклеточном раке головы и шеи (см. таблицу в приложении). Как и в случае с нормальной стволовой клеткой, в опухолевой клетке CD44 выполняет ряд функций, связанных с миграцией клетки (в частности с инвазией и метастазированием), взаимодействием с внеклеточным матриксом и окружающими клетками. Одним из наиболее убедительных доказательств участия CD44 в прогрессии опухоли служит тот факт, что у трансгенных мышей Gan (K19-Wnt1/C2mE; мыши с экспрессией Wnt1, COX-2 и mGES-1 под промотором гена кератина 19 в слизистом эпителии желудка), имеющих фенотип $\mathrm{CD}_{4} 4^{+/+}$ развиваются значительно большие по размеру опухоли желудка, чем у мышей с фенотипом CD44 ${ }^{-/}$[60]. Внутриклеточный домен CD44 участвует в связывании с транскрипционным фактором STAT3 и совместно с ним регулирует транскрипционную программу, влияющую на формирование клонов и туморогенность опухолевых клеток in vitro и in vivo [61]. CD44, по-видимому, также вовлечён 


\section{МОЛЕКУЛЯРНЫЕ МАРКЕРЫ РАКОВЫХ СТВОЛОВЫХ КЛЕТОК}

в эпителиально-мезенхимальный переход, который свойственен РСК многих опухолей [62]. Так, в случае клеток аденокарциномы желудка, приобретающих мезенхимальный фенотип вследствие заражения Helicobacter pylori, происходит позитивная регуляция экспрессии CD44. Более того, в иммунодефицитных мышах CD44 ${ }^{\text {high }}$ клетки демонстрируют не только мезенхимальный фенотип, но и более высокую туморогенность в сравнении с CD44 ${ }^{\text {low }}$ клетками [63]. Участие CD44 в процессе метастазирования была также показана в ряде работ. Например, у клеток аденокарциномы поджелудочной железы крысы BSp73ASML существенно снижается способность к метастазированию при нокдауне изоформы CD44v4-v7 [64].

Обращаясь к мета-анализам клинических данных, необходимо отметить корреляцию между экспрессией $\mathrm{CD} 44$, более низкой общей выживаемостью $[12,65]$ и метастазами в лимфатические узлы $[12,65,66]$ при карциноме желудка. В этих работах также показана взаимосвязь между уровнем экспрессии изоформы CD44v6 и метастазами в лимфатические узлы [12, 66, 67]. В случае немелкоклеточного рака лёгких экспрессия этой изоформы также коррелирует с метастазами в лимфатические узлы и гистотипом опухоли (плоскоклеточный тип рака) [68, 69]. Повышенная экспрессия CD44v6 связана с пониженной пятилетней выживаемостью при карциноме гортани и глотки $[70,71]$, метастазами в лимфатические узлы в случае рака пищевода [72] и плохим прогнозом гепатоклеточной карциномы [73]. В случае карциномы почки экспрессия CD44 коррелирует с более низкой общей и безрецидивной выживаемостью, высокой стадией заболевания, микрососудистой инвазией и рецидивами [74]. Таким образом, во всех представленных выше мета-анализах демонстрируется четкая зависимость между экспрессией маркера CD44/CD44v6 и неблагоприятным прогнозом течения онкологического заболевания. Исключениями являются остеосаркома [75] и карцинома ротовой полости [71], при мета-анализе клинических данных которых такая зависимость не была обнаружена.

Таким образом, можно с уверенностью сказать, что разнообразные процессы, связанные с функцией CD44, имеют место как в нормальных стволовых клетках, так и в РСК. При этом CD44 выступает интегратором различных сигналов от молекул внеклеточного матрикса, растворимых факторов, рецепторов и внутриклеточных стимулов, и тем самым участвует в регуляции пролиферации, миграции и дифференцировки клеток.

\subsection{EpCAM (CD326)}

EpCAM (Epithelial Cell Adhesion Molecule; молекула клеточной адгезии эпителия) - гликопротеин, принадлежащий к первому классу мембранных белков и имеющий молекулярный вес в районе 40 кДа. Он состоит из внеклеточной части, которая имеет EGF-подобный домен и домен, подобный TY-повтору (TY, тиреоглобулин), одного трансмембранного участка и короткого (26 аминокислотных остатков) цитоплазматического конца. ЕрСАМ был открыт в 1979 г. как мишень для моноклональных антител против клеток колоректальной карциномы $[16,76]$. C тех пор его неоднократно "открывали" другие исследователи, что привело к появлению более двух десятков различных наименований. Лишь в 2007 году за ним было окончательно закреплено нынешнее название - EpCAM (CD326). Ген ЕрCAM состоит из девяти экзонов и является высококонсервативным среди высших позвоночных. Гомология последовательностей этого гена у человека и мыши достигает 81\% [77]. ЕрСАМ экспрессируется в подавляющем большинстве эпителиальных тканей (кроме терминально дифференцированного плоского эпителия), в происходящих из них карциномах, прогениторных и стволовых клетках, а также в некоторых ретинобластомах и гепатоклеточных карциномах [16]. Его экспрессия не обнаружена в нейроэндокринной, мышечной, мезенхимальной, лимфоидной ткани, а также в меланомах [78].

ЕрСАМ ответственен за $\mathrm{Ca}^{2+}$-независимую гомотипическую межклеточную адгезию. В нормальных клетках ЕрСАМ локализуется в основном в базолатеральной мембране, а также в плотных контактах [79]. Как показывают исследования, там он может связываться с клаудином-7, белком, принадлежащим к семейству клаудинов, главных регуляторов параклеточного барьера [80]. По-видимому, функции ЕрСАМ не ограничиваются обычной эффекторной ролью в процессе адгезии. Так, например, показано, что сила межклеточной адгезии существенно уменьшается при повышении экспрессии ЕрСАМ в клетках, адгезия которых основана на классических молекулах, таких как Е- и N-кадгерин [81]. Вероятно, ЕрСАМ является не просто участником межклеточной адгезии, но и модулятором этого процесса. Помимо участия в клеточной адгезии ЕрСАМ может регулировать транскрипционную программу клетки, оказывая влияние на процессы пролиферации и апоптоза [82-84]. Подобную регуляцию функций клетки ЕрСАМ может осуществлять благодаря регулируемому внутримембранному протеолизу (RIP, regulated intramembrane proteolysis), который инициируется при димеризации ЕрСАМ. В результате протеолиза происходит высвобождение внеклеточной его части (EpEX, EpCAM extracellular domain) в окружающую среду, а внутренней его части (EpICD, ЕрCAM intracellular domain) в цитоплазму [85, 86]. Именно EpICD, связываясь с белками-посредниками, может проникать в ядро клетки и индуцировать траснкрипцию ряда генов.

Многие молекулы клеточной адгезии вовлечены в процесс раннего эмбриогенеза и ЕрСАМ не является исключением. Экспрессия ЕрСАМ обнаружена на таких этапах раннего эмбриогенеза крысы как оплодотворенный ооцит, стадия двух бластомеров, морула [87]. В других работах показано, что в процессе эмбриогенеза экспрессия ЕрСАМ индуцируется при созревании и дифференцировке различных структур, как это происходит, например, в случае развития почки [16]. В ряде эпителиальных тканей пролиферативная активность клеток 
Ким и др.

коррелирует с увеличением экспрессии ЕрСАМ, а дифференцировка, наоборот, с уменьшением экспрессии. Так, в случае эпителия кишечника крысы можно наблюдать градиентное уменьшение ЕрСАМ от крипт кишечника, в которых располагаются стволовые клетки, до кишечной ворсинки [88]. Экспрессия ЕрСАМ была также обнаружена в фетальных клетках печени человека; в гепатоцитах печени взрослого экспрессия ЕрСАМ ограничена случаем регенеративных процессов [89]. Суммируя вышеописанные факты можно отметить, что в начальной фазе морфогенеза ЕрСАМ экспрессируется не только в эпителиальных предшественниках, но и в клетках с более высокой степенью потентности, тогда как на поздних этапах экспрессия ЕрСАМ обнаруживается в эпителиальных клетках и полностью отсутствует в других терминально дифференцированных клетках. Участие ЕрСАМ в программе стволовой клетки подробно рассмотрено в обзоре [16].

ЕрСАМ, как и другие молекулы клеточной адгезии, участвует в развитии целого ряда опухолей. При этом его локализация в процессе канцерогенеза может существенно меняться: если в здоровой клетке ЕрСАМ локализуется в латеральной, базолатеральной мембране и плотных контактах, то в опухолевой клетке его локализация зависит от типа опухоли. Так, в клетках высоко дифференцированной аденокарциномы толстого кишечника экспрессия ЕрСАМ обнаруживается в базолатеральной части клетки, тогда как в случае карциномы толстой кишки с умеренной дифференцировкой - как в мембране, так и в цитоплазме [90]. В опухолевых клетках толстого кишечника экспрессия ЕрСАМ увеличивается в процессе развития заболевания [91]. Участие этого маркера в прогрессии опухоли также подтверждают данные с использованием иммунодефицитных мышей. При инъекции клеток линии НЕК293, трансфицированных либо полным ЕрСАМ, либо EpICD, развитие опухоли обнаружено у всех мышей, а при инъекции нетрансфицированных клеток развитие опухоли обнаружено только у одной из восьми мышей [85]. Необходимо отметить, что в ряде экспериментов с мышиным гомологом трансфицированные ЕрСАМ клетки, наоборот, обладали меньшей скоростью роста, способностью к инвазии, а также формированию колоний, чем нетрансфицированные [92]. Касаясь молекулярных аспектов онкогенного потенциала ЕрСАМ, необходимо отметить тот факт, что его транскрипция подавляется одним из главных белков-онкосупрессоров р53, что приводит к уменьшению инвазии клеток карциномы молочной железы [93]. По-видимому, в прогрессии опухоли ЕрСАМ участвует благодаря своему цитоплазматическому домену EpICD, обладающему функциями транскрипционного фактора.

При изучении туморогенных свойств различных популяций ЕрСАМ чаще всего используют для отделения трансформированных эпителиальных клеток карцином от окружающих стромальных клеток и клеток крови. Обращаясь к результатам работ, посвященных изучению корреляции экспрессии
ЕрСАМ с прогнозом и клинико-патологическими характеристиками заболевания, необходимо отметить тот факт, что нам удалось найти только один мета-анализ на эту тему. В нём показана корреляция между экспрессией ЕрСАМ и умеренным, а также высоким уровнем клеточной атипии при лейомиосаркоме [94]. Кроме того, в ряде оригинальных работ приведены данные о корреляции между высоким уровнем экспрессии ЕрСАМ и плохим прогнозом течения заболевания для опухолей молочной железы, желчного пузыря, мочевого пузыря, ампулярного рака и карциномы поджелудочной железы на поздних стадиях [95-98]. Обратная корреляция показана для рака почки [99]. Интересно, что коррелировать с прогнозом заболевания может не только уровень экспрессии ЕрСАМ, но и его клеточная локализация. Так, в случае с раком щитовидной железы цитоплазматическая локализация EpICD и потеря $\mathrm{EpEX}$ коррелирует с более низкой общей выживаемостью и с наиболее агрессивным анапластическим типом рака щитовидной железы [100].

Таким образом, можно с определённостью утверждать, что ЕрСАМ представляет собой крайне интересный и перспективный маркер РСК с пока ещё не выясненными до конца функциями. С одной стороны, существует множество работ, посвященных его экспрессии в различных нормальных тканях и опухолях, с другой стороны молекулярная основа активности ЕрСАМ и его молекулярные партнеры только-только начинают выявляться.

\section{4. РАКОВЫЕ СТВОЛОВЫЕ КЛЕТКИ КАК МИШЕНЬ ДЛЯ ПРОТИВООПУХОЛЕВОЙ ТЕРАПИИ}

Многочисленные свидетельства того, что РСК инициируют рост и метастазирование опухоли, подчеркивают необходимость создания новых противоопухолевых препаратов, уничтожающих именно данную популяцию клеток. В настоящее время уже разрабатываются подходы направленного воздействия на РСК, включая таргетную терапию и иммунотерапию.

Одним из методов таргетной терапии является введение антител к поверхностным белкам клеточной мембраны РСК. Например, в исследованиях, посвященных острой миелоидной лейкемии [101] и гепатоцеллюлярной карциноме [102], введение антител против CD44 приводит к элиминации РСК и препятствует образованию и росту опухоли у иммунодефицитных мышей. Разновидностью этого подхода является разработка биспецифичных антител, распознающих одновременно и маркеры РСК, и опухолевые антигены, что увеличивает специфичность воздействия на РСК [103]. Например, было продемонстрировано, что введение иммунодефицитным мышам клеток глиобластомы человека совместно с антителами против EGFRvIII/CD133 снижало их опухолеобразующую способность лучше, чем при использовании любого агента, направленного против единичного эпитопа [104]. 


\section{МОЛЕКУЛЯРНЫЕ МАРКЕРЫ РАКОВЫХ СТВОЛОВЫХ КЛЕТОК}

Другой подход - преодоление устойчивости РСК к химио- и радиотерапии - может быть эффективен в качестве адъювантной терапии. Например, в серии экспериментов по ксенотрансплантации клеток меланомы человека иммунодефицитным мышам, ингибирование усиленного выведения лекарственных препаратов из РСК достигали посредством воздействия антителами к АВСВ5-транспортерам. Это приводило к остановке роста опухоли и сенсибилизации раковых клеток к химиотерапии $[105,106]$. Также было показано, что чувствительность раковых клеток к апоптотическому действию химио- и радиотерапии увеличивалась при ингибировании транскрипционного фактора NF-кB [107].

Терапия, направленная на индукцию дифференцировки РСК в более зрелые раковые клетки, ограничивает их пролиферативный и инвазивный потенциал. Например, селективный ионофор калия салиномицин индуцировал эпителиальную дифференцировку раковых клеток и уменьшал долю РСК молочной железы. При этом клетки, подвергавшиеся действию салиномицина, обладали более слабой способностью индуцировать опухоли у мышей [108]. В исследовании, посвящённом колоректальному раку, белок ВМР4 активировал программу дифференцировки и стимулировал апоптоз РСК, посредством активации сигнального пути PI3K/AKT. Совместное введение ВМР4 с оксалиплатином и 5-фторурацилом иммунодефицитным мышам с опухолевыми ксенотрансплантатами, образованными РСК колоректального рака, индуцировало у них полную, продолжительную регрессию опухоли [109].

Перспективным направлением таргетной терапии является блокировка сигнальных путей (таких как Wnt и Notch), задействованных в самовоспроизведении РСК. Недавно были идентифицированы небольшие молекулы, ингибирующие данные сигнальные пути при колоректальном раке [110].

Альтернативным подходом воздействия на РСК является иммунотерапия. Наиболее исследованным её направлением является применение дендритноклеточных (ДК) вакцин. ДК-вакцинация способствует повышению исходно низкой иммуногенности РСК. В работе, посвященной изучению глиобластомы, нейросферы, обогащённые РСК, были использованы для загрузки ДК и вызывали сильный лечебный эффект при вакцинации сингенных мышей. Этот эффект был связан с инфильтрацией опухоли $\mathrm{CD}^{+}$и $\mathrm{CD}^{+} \mathrm{T}$-клетками. Культивирование нейросфер ex vivo увеличивало экспрессию МНС и костимулирующих молекул (CD80; CD86) на мембране РCK [111]. Вакцинация сингенных иммунокомпетентных мышей ДК, загруженными лизатами РСК из клеточных линий меланомы и плоскоклеточного рака, приводила к развитию у них противоопухолевого иммунитета. Сыворотка от вакцинированных мышей содержала высокие уровни $\mathrm{IgG}$, который связывался с РСК, что приводило к их лизису в присутствии белков системы комплемента. Цитотоксические лимфоциты, полученные из мононуклеаров периферической крови или спленоцитов вакцинированных мышей, были способны убивать РСК in vitro [112].

Другим направлением иммунотерапии является введение различных типов иммунных эффекторных клеток, например, NK-клеток (NK - natural killers; естественные киллеры) и CIK-клеток (CIK - cytokineinduced killers; цитокин-индуцированные клеткикиллеры). Так, в исследовании с использованием ксенотрансплантационной модели колоректальной аденокарциномы человека в иммунодефицитных мышах, было показано, что NK-клетки преимущественно распознают и уничтожают РСК. Это коррелирует с повышенной экспрессией на мембране РСК лигандов для рецепторов натуральной цитотоксичности (NKp30; NKp44) при пониженной экспрессии МНС класса I по сравнению с дифференцированными раковыми клетками [113].

CIK-клетки получают ex vivo в ходе размножения и активации Т-лимфоцитов и NK-клеток [114]. В двух работах продемонстрировано, что СІК-клетки эффективно убивали РСК меланомы, саркомы кости и мягких тканей in vitro. Эти данные были подтверждены in vivo в работе с использованием ксенотрансплантационной модели саркомы в иммунодефицитных мышах, где СІК-клетки были способны элиминировать РСК $[115,116]$.

Очевидно, что дальнейшая разработка и введение в клиническую практику новых препаратов, направленных против РСК, позволит создать более эффективные и индивидуализированные схемы комбинированного лечения онкологических заболеваний.

\section{5. ПЕРСПЕКТИВЫ РАЗВИТИЯ ТЕОРИИ РАКОВОЙ СТВОЛОВОЙ КЛЕТКИ И ПОИСК НОВЫХ МОЛЕКУЛЯРНЫХ МАРКЕРОВ ОПУХОЛЬ-ИНИЦИИРУЮЩИХ ПОПУЛЯЦИЙ}

Теория РСК в её классическом виде исходит из того, что туморогенными свойствами обладает только популяция РСК, тогда как более дифференцированные опухолевые клетки теряют способность инициировать опухоль. Исключительная туморогенность РСК подтверждается экспериментально в серии сравнительных пассажей in vivo c доказательством восстановления на каждом этапе всех клеточных популяций исходной опухоли со всеми их фенотипическими и функциональными особенностями [5]. Однако подобные доказательства встречаются довольно редко, можно привести лишь ограниченный список работ, свидетельствующих об исключительной туморогенности той или иной популяции РСК. По-видимому, использование столь строгих критериев оправдано лишь для ограниченного количества нозологических форм опухолевых заболеваний [14].

В свою очередь, в большинстве проанализированных нами работ, авторы демонстрируют лишь сверхтуморогенные свойства РСК, при этом остальные популяции опухолевых клеток также обладают способностью 
к восстановлению опухоли, но при введении большего количества клеток или за более продолжительный период времени. Результаты этих работ в свете классической теории РСК часто объясняются технической невозможностью полного разделения изучаемых популяций и отсутствием подходящих маркеров для выделения чистой популяции РСК.

В действительности, сверхтуморогенные свойства популяции РСК могут возникать не из-за наличия “стволовой программы”, а из-за повышенной пролиферации этих клеток, что идет вразрез с представлениями о стволовых клетках, как о клетках, обладающих повышенным пролиферативным потенциалом, но не повышенной пролиферативной активностью. Подобные сомнения находят выражение в том, что в научной литературе вместо термина "раковая стволовая клетка" всё чаще используется термин "раковая инициирующая клетка" (РИК) [117], который отражает лишь способность этих клеток эффективно инициировать развитие опухоли при ксенотрансплантации иммунодефицитным животным. В этой связи, крайне важно проведение исследований, направленных на выявление в РСК эпигенетических и экспрессионных паттернов, характерных для нормальных стволовых клеток. Применение биоинформационных подходов будет способствовать идентификации новых дифференциальных маркеров РСК, обладающих большей специфичностью, а также позволит проследить вовлеченность маркерных молекул в биологию РСК. В результате будут созданы условия для более корректной изоляции популяций РСК из различных опухолей, а также расширены представления о молекулярных особенностях этих клеток. Пока же мы можем с уверенностью сказать, что феномен опухолевой клеточной гетерогенности существенно шире изначальной концепции РСК. Это позволяет рассчитывать на то, что будет сформирована интегральная теория, которая объединит концепции РСК/РИК и клональной эволюции, как это, например, попытался сделать в своей работе Clevers [118]. В свою очередь, выявление новых молекулярных маркеров РСК и более глубокое понимание молекулярно-биологических особенностей этих клеток, вне всякого сомнения, внесут существенный вклад в решение проблемы терапии онкологических заболеваний.

Извлечение $u$ предварительный анализ информации о молекулярных маркерах РСК был выполнен при финансовой поддержке РФФИ (грант № 15-59-31516). Системный обзор литературы по теме исследования был выполнен в рамках "Программы фундаментальных научных исследований государственных академий наук на 2013-2020 годы"”.

Приложение доступно в электронной версии статьи на сайте журнала (pbmc.ibmc.msk.ru).

\section{ЛИТЕРАТУРА}

1. Wright J. (1910) J. Exp. Med., 12(4), 556-561.

2. Clarkson B.D. (1969) Natl. Cancer Inst. Monogr., 30, 81-120.

3. Pierce G.B., Wallace C. (1971) Cancer Res., 31, 127-134.

4. Pierce G.B., Speers W.C. (1988) Cancer Res., 48, 1996-2004.

5. Bonnet D., Dick J.E. (1997) Nat. Med., 3(7), 730-737.

6. Yoo Y.D., Kwon Y.T. (2015) J Anal Sci Technol., 6(1), 28.

7. Li L., Neaves W.B. (2006) Cancer Res., 66(9), 4553-4557.

8. Li F., Tiede B., Massagué J., Kang Y. (2007) Cell Res., 17(1), 3-14.

9. Vidal S.J., Rodriguez-Bravo V., Galsky M., Cordon-Cardo C., Domingo-Domenech J. (2014) Oncogene, 33(36), 4451-4463.

10. Guo Z., Li L.Q., Jiang J.H., Ou C., Zeng L.X., Xiang B.D. (2014) World J. Gastroenterol., 20(8), 2098-2106.

11. Qu H., Li R., Liu Z., Zhang J., Luo R. (2013) Int. J. Clin. Exp. Pathol., 6(11), 2644-2650.

12. Wu Y., Li Z., Zhang C., Yu K., Teng Z., Zheng G., Wang S., Liu Y., Cui L., Yu X. (2015) Int. J. Clin. Exp. Med., 8(3), 3595-3606.

13. Nowell P.C. (1976) Science, 194(4260), 23-28.

14. Shackleton M., Quintana E., Fearon E.R., Morrison S.J. (2009) Cell, 138(5), 822-829.

15. Ito R., Takahashi T., Katano I., Ito M. (2012) Cell Mol. Immunol., 9(3), 208-214.

16. Trzpis M., McLaughlin P.M., de Leij L.M., Harmsen M.C. (2007) Am. J. Pathol., 171(2), 386-395.

17. Miraglia S., Godfrey W., Yin A.H., Atkins K., Warnke R., Holden J.T., Bray R.A., Waller E.K., Buck D.W. (1997) Blood, 90(12), 5013-5021.

18. Fargeas C.A., Huttner W.B., Corbeil D. (2007) Tissue Antigens, 69(6), 602-606.

19. Yin A.H., Miraglia S., Zanjani E.D., Almeida-Porada G., Ogawa M., Leary A.G., Olweus J., Kearney J., Buck D.W. (1997) Blood, 90(12), 5002-5012.

20. Sugiyama T., Rodriguez R.T., McLean G.W., Kim S.K. (2007) Proc. Natl. Acad. Sci. USA, 104(1), 175-180.

21. Uchida N., Buck D.W., He D., Reitsma M.J., Masek M., Phan T.V., Tsukamoto A.S., Gage F.H., Weissman I.L. (2000) Proc. Natl. Acad. Sci. USA, 97(26), 14720-14725.

22. Bertolini G., Roz L., Perego P., Tortoreto M., Fontanella E., Gatti L., Pratesi G., Fabbri A., Andriani F., Tinelli S. et al. (2009) Proc. Natl. Acad. Sci. USA, 106(38), 16281-16286.

23. O'Brien C.A., Pollett A., Gallinger S., Dick J.E. (2007) Nature, 445(7123), 106-110.

24. Hermann P.C., Huber S.L., Herrler T., Aicher A., Ellwart J.W., Guba M., Bruns C.J., Heeschen C. (2007) Cell Stem Cell, 1(3), 313-323.

25. Zacchigna S., Oh H., Wilsch-Bräuninger M., Missol-Kolka E., Jászai J., Jansen S., Tanimoto N., Tonagel F., Seeliger M., Huttner W.B. et al. (2009) J. Neurosci., 29(7), 2297-2308.

26. Corbeil D., Marzesco A.M., Wilsch-Bräuninger M., Huttner W.B. (2010) FEBS Lett., 584(9), 1659-1664.

27. Weigmann A., Corbeil D., Hellwig A., Huttner W.B. (1997) Proc. Natl. Acad. Sci. USA, 94(23), 12425-12430.

28. Marzesco A.M., Janich P., Wilsch-Bräuninger M., Dubreuil V., Langenfeld K., Corbeil D., Huttner W.B. (2005) J. Cell Sci., 118(13), 2849-2858.

29. Dubreuil V., Marzesco A.M., Corbeil D., Huttner W.B., Wilsch-Bräuninger M. (2007) J. Cell Biol., 176(4), 483-495.

30. Röper K., Corbeil D., Huttner W.B. (2000) Nat. Cell Biol., 2(9), 582-592. 


\section{МОЛЕКУЛЯРНЫЕ МАРКЕРЫ РАКОВЫХ СТВОЛОВЫХ КЛЕТОК}

31. Taïeb N., Maresca M., Guo X.J., Garmy N., Fantini J., Yahi N. (2009) Cancer Lett., 278(2), 164-173.

32. Wang W., Chen Y., Deng J., Zhou J., Zhou Y., Wang S., Zhou J. (2014) Tumour Biol., 35(10), 9769-9775.

33. Wu H., Qi X.W., Yan G.N., Zhang Q.B., Xu C., Bian X.W. (2014) PLoS One, 9(6), e100168.

34. Tan Y., Chen B., Xu W., Zhao W., Wu J. (2014) Mol. Clin. Oncol., 2(1), 111-115.

35. Wu B., Sun C., Feng F., Ge M., Xia L. (2015) J. Exp. Clin. Cancer Res., 34, 44

36. Han M., Guo L., Zhang Y., Huang B., Chen A., Chen W., Liu X., Sun S., Wang K., Liu A., Li X. (2016) Mol. Neurobiol., 53(1), 720-727.

37. Zhang W., Chen H., Lv S., Yang H. (2015) Mol. Neurobiol. Epub ahead of print.

38. Wang K., Xu J., Zhang J., Huang J. (2012) BMC Cancer, 12, 573.

39. Chen S., Song X., Chen Z., Li X., Li M., Liu H., Li J. (2013) PLoS One, 8(2), e56380.

40. Wen L., Chen X.Z., Yang K., Chen Z.X., Zhang B., Chen J.P., Zhou Z.G., Mo X.M., Hu J.K. (2013) PLoS One, 8(3), e59154.

41. Li Y.M., Guo Y.S., Ma B., Zang Y., Wei T., Liang G.F., Fan X., Cui S.Q., Jiang J.L., Tang J., Chen Z.N. (2015) Oncotarget. DOI: 10.18632/oncotarget.5714

42. Zhong C., Wu J.D., Fang M.M., Pu L.Y. (2015) Tumor Biol., 36(10), 7623-7630.

43. Zhou Q., Chen A., Song H., Tao J., Yang H., Zuo M. (2015) Int. J. Clin. Exp. Med., 8(3), 3080-3088.

44. Williams K., Motiani K., Giridhar P.V., Kasper S. (2013) Exp. Biol. Med. (Maywood), 238(3), 324-338.

45. Aruffo A., Stamenkovic I., Melnick M., Underhill C.B., Seed B. (1990) Cell, 61(7), 1303-1313.

46. Ishii S., Ford R., Thomas P., Nachman A., Steele G.Jr., Jessup J.M. (1993) Surg. Oncol., 2(4), 255-264.

47. Jalkanen S., Jalkanen M. (1992) J. Cell Biol., 116(3), 817-825.

48. Hanley W.D., Napier S.L., Burdick M.M., Schnaar R.L., Sackstein R., Konstantopoulos K. (2006) FASEB J., 20 (2), 337-339.

49. Tremmel M., Matzke A., Albrecht I., Laib A.M., Olaku V., Ballmer-Hofer K., Christofori G. Héroult M., Augustin H.G., Ponta H., Orian-Rousseau V. (2009) Blood, 114(25), 5236-5244.

50. Bennett K.L., Jackson D.G, Simon J.C., Tanczos E., Peach R., Modrell B., Stamenkovic I., Plowman G., Aruffo A. (1995) J. Cell Biol., 128(4), 687-698.

51. Ponta H., Sherman L., Herrlich P.A. (2003) Nat. Rev. Mol. Cell Biol., 4(1), 33-45.

52. Janiszewska M., De Vito C., Le Bitoux M.A., Fusco C., Stamenkovic I. (2010) J. Biol. Chem., 285(40), 30548-30557.

53. Lee J.L., Wang M.J., Chen J.Y. (2009) J. Cell Biol., 185(6), 949-957.

54. Solis M.A., Chen Y.H., Wong T.Y., Bittencourt V.Z., Lin Y.C., Huang L.L. (2012) Biochem. Res. Int., 2012, 346972.

55. Shukla S., Nair R., Rolle M.W., Braun K.R., Chan C.K., Johnson P.Y., Wight T.N., McDevitt T.C. (2010) J. Histochem. Cytochem., 58(4), 345-358.

56. Knudson W., Bartnik E., Knudson C.B. (1993) Proc. Natl. Acad. Sci. USA, 90(9), 4003-4007.

57. Sackstein R. (2011) Curr. Opin. Hematol., 18(4), 239-248.

58. Zhu H., Mitsuhashi N., Klein A., Barsky L.W., Weinberg K., Barr M.L., Demetriou A., Wu G.D. (2006) Stem Cells, 24(4), 928-935.

59. Márquez C., Trigueros C., Fernández E., Toribio M.L. (1995) J. Exp. Med., 181(2), 475-483.
60. Ishimoto T., Nagano O., Yae T., Tamada M., Motohara T., Oshima H., Oshima M., Ikeda T., Asaba R., Yagi H. et al. (2011) Cancer Cell, 19(3), 387-400.

61. Su Y.J., Lai H.M., Chang Y.W., Chen G.Y., Lee J.L. (2011) EMBO J., 30(15), 3186-3199.

62. Singh A., Settleman J. (2010) Oncogene, 29(34), 4741-4751.

63. Bessède E., Staedel C., Acuña Amador L.A., Nguyen P.H. Chambonnier L., Hatakeyama M., Belleannée G., Mégraud F., Varon C. (2014) Oncogene, 33(32), 4123-4131.

64. Jung T., Castellana D., Klingbeil P., Cuesta Hernández I., Vitacolonna M., Orlicky D.J., Roffler S.R., Brodt P., Zöller M. (2009) Neoplasia, 11(10), 1093-1105.

65. Chen Y., Fu Z., Xu S., Xu Y., Xu P. (2014) Biomed. Pharmacother., 68(6), 693-697.

66. Wang W., Dong L.P., Zhang N., Zhao C.H. (2014) Int. J. Clin. Exp. Med., 7(12), 5059-5066.

67. Chen J., Li T., Liu Q., Jiao H., Yang W., Liu X., Huo Z. (2014) PLoS One, 9(3), e91842.

68. Luo Z., Wu R.R., Lv L., Li P., Zhang L.Y., Hao Q.L., Li W. (2014) Int. J. Clin. Exp. Pathol., 7(7), 3632-3646.

69. Zhao S., He J.L., Qiu Z.X., Chen N.Y., Luo Z., Chen B.J., Li W.M. (2014) Asian Pac. J. Cancer Prev., 15(16), 6761-6766

70. Chai L., Liu H., Zhang Z., Wang F., Wang Q., Zhou S., Wang S. (2014) Tohoku J. Exp. Med., 232(1), 9-19.

71. Chen J., Zhou J., Lu J., Xiong H., Shi X., Gong L. (2014) BMC Cancer, 14, 15.

72. Ни B., Luo W., Hu R.T., Zhou Y., Qin S.Y., Jiang H.X (2015) Medicine (Baltimore), 94(31), e1238.

73. Fu Y., Geng Y., Yang N., Zhu N., Wang C.Z., Su X.C., Zhang H.B. (2015) Clin. Res. Hepatol. Gastroenterol., 39(6), 736-739.

74. Li X., Ma X., Chen L., Gu L., Zhang Y., Zhang F., Ouyang Y., Gao Y., Huang Q., Zhang X. (2015) Sci. Rep., 5, 13157.

75. Liu Y., Wu Y., Gu S., Sun Z., Rui Y., Wang J., Lu Y., Li H. $X u$ K., Sheng P. (2014) Diagn. Pathol., 9, 140

76. Herlyn M., Steplewski Z., Herlyn D., Koprowski H. (1979) Proc. Natl. Acad. Sci. USA, 76(3), 1438-1442.

77. Schnell U., Cirulli V., Giepmans B.N. (2013) Biochim. Biophys. Acta, 1828(8), 1989-2001.

78. Patriarca C., Macchi R.M., Marschner A.K., Mellstedt H. (2012) Cancer Treat. Rev., 38(1), 68-75.

79. Litvinov S.V., Velders M.P., Bakker H.A., Fleuren G.J., Warnaar S.O. (1994) J. Cell Biol., 125(2), 437-446.

80. Ladwein M., Pape U.F., Schmidt D.S., Schnulzer M., Fiedler S., Langbein L., Franke W.W., Moldenhauer G., Zöller M. (2005) Exp. Cell Res., 309(2), 345-357.

81. Litvinov S.V., Balzar M., Winter M.J., Bakker H.A., Briaire-de Bruijn I.H., Prins F., Fleuren G.J., Warnaar S.O. (1997) J. Cell Biol., 139(5), 1337-1348.

82. Münz M., Kieu C., Mack B., Schmitt B., Zeidler R., Gires $O$. (2004) Oncogene, 23(34), 5748-5758.

83. Maaser K., Borlak J. (2008) Br. J. Cancer, 99(10), 1635-1643.

84. Chaves-Pérez A., Mack B., Maetzel D., Kremling H., Eggert C., Harréus U., Gires O. (2013) Oncogene, 32(5), 641-650.

85. Maetzel D., Denzel S., Mack B., Canis M., Went P., Benk M., Kieu C., Papior P., Baeuerle P.A., Munz M., Gires $O$. (2009) Nat. Cell Biol., 11(2), 162-171.

86. Schnell U., Kuipers J., Giepmans B.N. (2013) Biosci. Rep., 33(2), e00030.

87. Tarmann T., Dohr G., Schiechl H., Barth S., Hartmann M. (1990) Acta Anat. (Basel), 137(2), 141-145.

88. Schiechl H., Dohr G. (1987) Histochemistry, 87(5), 491-498. 
89. de Boer C.J., van Krieken J.H., Janssen-van Rhijn C.M., Litvinov S.V. (1999) J. Pathol., 188(2), 201-206.

90. Ogura E., Senzaki H., Yoshizawa K., Hioki K., Tsubura A. (1998) Anticancer Res., 18(5B), 3669-3675.

91. Xie X., Wang C.Y., Cao Y.X., Wang W., Zhuang R., Chen L.H., Dang N.N., Fang L., Jin B.Q. (2005) World J. Gastroenterol., 11(3), 344-347.

92. Basak S., Speicher D., Eck S., Wunner W., Maul G., Simmons M.S., Herlyn D. (1998) J. Natl. Cancer Inst., 90(9), 691-697.

93. Sankpal N.V., Willman M.W., Fleming T.P., Mayfield J.D., Gillanders W.E. (2009) Cancer Res., 69(3), 753-757.

94. Ward K., Amaya C., Verma K., Tran D., Diaz D., Torabi A., Bryan B.A. (2015) Mol. Clin. Oncol., 3(1), 31-36.

95. Spizzo G., Obrist P., Ensinger C., Theurl I., Dünser M., Ramoni A., Gunsilius E., Eibl G., Mikuz G., Gastl G. (2002) Int. J. Cancer, 98(6), 883-888.

96. Varga M., Obrist P., Schneeberger S., Mühlmann G., Felgel-Farnholz C., Fong D., Zitt M., Brunhuber T., Schäfer G., Gastl G., Spizzo G. (2004) Clin. Cancer Res., 10(9), 3131-3136.

97. Brunner A., Schaefer G., Veits L., Brunner B., Prelog M., Ensinger C. (2008) Anticancer Res., 28(1A), 125-128.

98. Fong D., Steurer M., Obrist P., Barbieri V., Margreiter R., Amberger A., Laimer K., Gastl G., Tzankov A., Spizzo G. (2008) J. Clin. Pathol., 61(1), 31-35.

99. Seligson D.B., Pantuck A.J., Liu X., Huang Y., Horvath S., Bui M.H., Han K.R., Correa A.J., Eeva M., Tze S., Belldegrun A.S., Figlin R.A. (2004) Clin. Cancer Res., 10(8), 2659-2669.

100. Ralhan R., Cao J., Lim T., Macmillan C., Freeman J.L., Walfish P.G. (2010) BMC Cancer, 10, 331.

101. Jin L., Hope K.J., Zhai Q., Smadja-Joffe F., Dick J.E. (2006) Nat. Med., 12, 1167-1174.

102. Yang Z.F., Ho D.W., Ng M.N., Lau C.K., Yu W.C., Ngai P., Chu P.W., Lam C.T., Poon R.T., Fan S.T. (2008) Cancer Cell, 13(2), 153-166.

103. Deonarain M.P., Kousparou C.A., Epenetos A.A. (2009) MAbs, 1(1), 12-25.

104. Emlet D.R., Gupta P., Holgado-Madruga M., Del Vecchio C.A., Mitra S.S., Han S.Y., Li G., Jensen K.C., Vogel H., Xu L.W., Skirboll S.S., Wong A.J. (2014) Cancer Res., 74(4), 1238-1249.
105. Schatton T., Murphy G.F., Frank N.Y., Yamaura K., Waaga-Gasser A.M., Gasser M., Zhan Q., Jordan S., Duncan L.M., Weishaupt C., Fuhlbrigge R.C., Kupper T.S., Sayegh M.H., Frank M.H. (2008) Nature, 451, 345-349.

106. Frank N.Y., Margaryan A., Huang Y., Schatton T., Waaga-Gasser A.M., Gasser M., Sayegh M.H., Sadee W., Frank M.H. (2005) Cancer Res., 65, 4320-4333.

107. Li F., Sethi G. (2010) Biochim. Biophys. Acta, 1805(2), 167-180.

108. Gupta P.B., Onder T.T., Jiang G., Tao K., Kuperwasser C., Weinberg R.A., Lander E.S. (2009) Cell, 138(4), 645-659.

109. Lombardo Y., Scopelliti A., Cammareri P., Todaro M., Iovino F., Ricci-Vitiani L., Gulotta G., Dieli F., de Maria R., Stassi G. (2011) Gastroenterology, 140(1), 297-309.

110. van Es J.H., Clevers H. (2005) Trends Mol. Med., 11, 496-502.

111. Pellegatta S., Poliani P.L., Corno D., Menghi F., Ghielmetti F., Suarez-Merino B., Caldera V., Nava S., Ravanini M., Facchetti F., Bruzzone M.G., Finocchiaro G. (2006) Cancer Res., 66(21), 10247-10252.

112. Ning N., Pan Q., Zheng F., Teitz-Tennenbaum S., Egenti M., Yet J., Li M., Ginestier C., Wicha M.S., Moyer J.S., Prince M.E., Xu Y., Zhang X.L., Huang S., Chang A.E., Li Q. (2012) Cancer Res., 72(7), 1853-1864.

113. Tallerico R., Todaro M., Di Franco S., Maccalli C., Garofalo C., Sottile R., Palmieri C., Tirinato L., Pangigadde P.N., La Rocca R. et al. (2013) J. Immunol., 190(5), 2381-2390.

114. Schmidt-Wolf I.G., Lefterova P., Mehta B.A., Fernandez L.P., Huhn D., Blume K.G., Weissman I.L., Negrin R.S. (1993) Exp. Hematol., 21(13), 1673-1679.

115. Gammaitoni L., Giraudo L., Leuci V., Todorovic M., Mesiano G., Picciotto F., Pisacane A., Zaccagna A., Volpe M.G., Gallo S. et al. (2013) Clin. Cancer Res., 19(16), 4347-4358.

116. Sangiolo D., Mesiano G., Gammaitoni L., Leuci V., Todorovic M., Giraudo L., Cammarata C., Dell'Aglio C., D'Ambrosio L., Pisacane A. et al. (2014) Cancer Res., 74(1), 119-129.

117. Dick J.E. (2008) Blood, 112(13), 4793-4807.

118. Clevers H. (2011) Nat Med., 17(3), 313-319.

Поступила: $\quad 30.03 .2016$. Принята к печати: 05. 04. 2016.

\title{
MOLECULAR MARKERS OF CANCER STEM CELLS VERIFIED IN VIVO
}

\author{
Y.S. Kim ${ }^{l}$, A.M. Kaidina ${ }^{l}$, J-H. Chiang', K.N. Yarygin', A.Yu. Lupatov ${ }^{l}$
}

${ }^{1}$ Institute of Biomedical Chemistry,

10 Pogodinskaya str., Moscow, 119121 Russia; tel.: +7(499)246-86-22; e-mail: yankimhcc@gmail.com. ${ }^{2}$ National Cheng Kung University, Tainan City, Taiwan

This systematic review aims to analyze molecular markers of cancer stem cells. Only studies that confirmed tumor-initiating capacity of this population by in vivo assay in immunodeficient mice were included. Final sample of papers that fully correspond with initial aim consists of 97 original studies. The results of their analysis reveal that markers commonly used for cancer stem cells deriving were as follows: CD133, CD44, ALDH, CD34, CD24 and EpCAM. The review also contains description of molecular features of some cancer stem cell markers, modern approaches to cancer treatment by targeting this population and brief assessment of cancer stem cell theory development.

Key words: cancer stem cell, molecular markers, systemic review 